\title{
The Predictive Value of CHA2DS2-VASc Score as a Predictor for Left Ventricular Thrombus After Acute Anterior ST-Elevation Myocardial Infarction: A Case- Control Retrospective Analysis
}

Nan Zheng

Cangzhou Central Hospital

Jun Zang ( $\boldsymbol{D}$ dr_zhangj@sina.com )

Cangzhou Central Hospital https://orcid.org/0000-0003-3787-875X

Research article

Keywords: CHA2DS2-VASc score, left ventricular thrombus, acute myocardial infarction, prediction

Posted Date: February 11th, 2021

DOl: https://doi.org/10.21203/rs.3.rs-215252/v1

License: (a) This work is licensed under a Creative Commons Attribution 4.0 International License.

Read Full License 


\section{Abstract}

Objective: To determine the predictive value of $\mathrm{CHA}_{2} \mathrm{DS}_{2}-\mathrm{VASc}$ score as a predictor for left ventricular thrombus after acute anterior ST-elevation myocardial infarction (STEMI).

Methods: We performed a case-control retrospective study of 30 patients with left ventricular thrombus (median age: 60.6 years, range: $38-75$ years old; 26 males, 74 females) and 60 age- and sex-matched controls without left ventricular thrombus. Correlation analysis was performed and receiver operating characteristic (ROC) curve was used to evaluate the predictive value of $\mathrm{CHA}_{2} \mathrm{DS}_{2}-\mathrm{VASc}$ score in detecting left ventricular thrombus.

Result: Patients with left ventricular thrombus after acute anterior STEMI had higher $\mathrm{CHA}_{2} \mathrm{DS}_{2}-$ VASc scores than controls $(P<0.001)$. Correlation analysis revealed that $\mathrm{CHA}_{2} \mathrm{DS}_{2}-\mathrm{VASc}$ scores were positively correlated with left ventricular thrombus after acute anterior STEMI $(r=0.413 ; P<0.001)$. Multiple logistic regression analyses indicated that $\mathrm{CHA}_{2} \mathrm{DS}_{2}-\mathrm{VASc}$ scores $(P=0.001)$ and heart failure $(P=0.023)$ were risk factors of left ventricular thrombus. The ROC curve of $\mathrm{CHA}_{2} \mathrm{DS}_{2}-\mathrm{VASc}$ scores revealed that area under curve was 0.746 (95\% confidence interval: $0.638-0.853, P<0.001$ ), sensibility was $86.7 \%$, and specificity was $50.0 \%$.

Conclusion: Patients with heart failure have a high incidence of left ventricular thrombus after acute anterior STEMI. $\mathrm{CHA}_{2} \mathrm{DS}_{2}-\mathrm{VASc}$ scores contribute to the prediction for left ventricular thrombus after acute anterior STEMI.

\section{Introduction}

Despite widespread uptake of primary percutaneous coronary intervention and improved overall periprocedural care, left ventricular thrombus remains a complication of acute anterior ST-elevation myocardial infarction (STEMI) and is associated with a high thromboembolic risk. ${ }^{1-3}$ Previousstudies reported that the incidence of left ventricular thrombus in patients presenting with acute anterior STEMI ranges from $2.1-12.3 \% .4,5$ Moreover, the detection, prevention, and treatment of this condition is replete with distinct challenges. ${ }^{6}$

Transesophageal echocardiography is considered the gold standard technique for left ventricular thrombus detection. ${ }^{7-9}$ However, it is time-consuming, expensive, and not readily available in all centers, especially when repeated examinations are necessary. Accumulating evidence illustrates the meaningful clinical information of $\mathrm{CHA}_{2} \mathrm{DS}_{2}$-VASc score in coronary heart and thrombotic diseases (whether diagnostic information or prognostic information). However, data regarding the role of the $\mathrm{CHA}_{2} \mathrm{DS}_{2}-$ VASc score in left ventricular thrombus after acute anterior STEMI are lacking. Thus, we performed this retrospective study to determine the predictive value of the $\mathrm{CHA}_{2} \mathrm{DS}_{2}-\mathrm{VASc}$ score as a predictor for left ventricular thrombus after acute anterior STEMI. 


\section{Methods}

\section{Ethics and consent}

This study was approved by the Medical Ethics Committee of Cangzhou Central Hospital (No. 2020-17001) and conducted in accordance with the Declaration of Helsinki. Informed consent was waived given the retrospective nature of this study. Patient information was anonymized prior to analysis.

\section{Patients}

We performed a case-control retrospective study of 30 patients with left ventricular thrombus (median age: 60.6 years, range: $38-75$ years old; 26 males, 74 females) and 60 age- and sex-matched controls without left ventricular thrombus. The inclusion criteria were as follows: (1) aged >18 years old, (2)with acute anterior STEMI diagnosed via coronary angiography and subsequently underwent revascularization, and (3) had complete medical data. Patients with any of the following criteria were excluded: (1) hypertrophic cardiomyopathy, (2) congenital heart disease, (3) organic valvular heart diseases, (4) history of any cardiac surgery and/or cardiac device insertion, and (5) significant associated systemic illness.

Acute left ventricular thrombus was defined as the presence of an echo dense mass seen in the left ventricular cavity on transthoracic echocardiogram within 7 days from acute anterior STEMI. ${ }^{10,11}$ STEMI was defined according to the WHO criteria as revised in 2000. ${ }^{12}$ Each patient received standard pharmacologic treatment according to AMI treatment guidelines. ${ }^{13}$

\section{Clinical Data}

Clinical baseline characteristics, including age, gender, body mass index, echocardiographic data, and medical history, were collected from medical record and analyzed. $\mathrm{CHA}_{2} \mathrm{DS}_{2}-\mathrm{VASc}$ score was calculated with 1 point assigned for a history of congestive heart failure, hypertension, 74 years $\geq$ age $\geq 65$ years, female, diabetes mellitus, and vascular disease and 2 points assigned for age $\geq 75$ years and a history of stroke or transient ischemic attacks. The maximum score is 9. The $\mathrm{CHA}_{2} \mathrm{DS}_{2}-\mathrm{VASc}$ score was calculated by the researcher without knowledge of the transthoracic echocardiogram result.

\section{Statistical analysis}

All statistical analyses were performed by SPSS for Windows version 13.0 (SPSS Inc., Chicago, IL). Twosample $t$ test was used to compare continuous variables with normal distribution and presented as mean \pm standard deviation, whereas nonparametric tests were utilized to compare continuous variables with abnormal distribution and presented as median (interquartile range). Chi-squared two-group proportion test was employed to compare categorical data. Correlation analyses using the Spearman method were 
conducted to test the relationship between $\mathrm{CHA}_{2} \mathrm{DS}_{2}-\mathrm{VASc}$ score and left ventricular thrombus. In univariate logistic analysis, when $P<0.10$, significant correlation factors were included in a forward stepwise multivariate logistic regression. The predictive value of $\mathrm{CHA}_{2} \mathrm{DS}_{2}-\mathrm{VASc}$ scores was evaluated by receiver operating characteristic (ROC) curve analyses, and their specificity and sensitivity in detecting left ventricular thrombus were analyzed. All tests were two-sided, and a $P$ value $<0.05$ was considered statistically significant.

\section{Results}

\section{Patient characteristics}

All patient characteristics are summarized in Table 1. The $\mathrm{CHA}_{2} \mathrm{DS}_{2}-\mathrm{VASc}$ scores of the patients ranged from 0 to 6 , and the mean score was 1.98. The patients with left ventricular thrombus were characterized by heart failure, stroke, vascular disease, and high $\mathrm{CHA}_{2} \mathrm{DS}_{2}-\mathrm{VASc}$ scores.

Table 1

General characteristics of the patients

\begin{tabular}{|llll|}
\hline & $\begin{array}{l}\text { Without left ventricular } \\
\text { thrombus }(\boldsymbol{n = 3 0})\end{array}$ & $\begin{array}{l}\text { With left ventricular } \\
\text { thrombus }(\boldsymbol{n = 6 0})\end{array}$ & $P$ value \\
\hline Age (years) & $63.00(16.00)$ & $62.50(14.00)$ & 0.901 \\
\hline Gender (male/female) & $4 / 26$ & $8 / 52$ & 1.000 \\
\hline hypertension (Yes/no) & $27 / 33$ & $19 / 11$ & 0.101 \\
\hline Diabetes mellitus (Yes/no) & $16 / 44$ & $8 / 22$ & 1.000 \\
\hline Heart failure (Yes/no) & $8 / 52$ & $14 / 16$ & 0.001 \\
\hline Stroke $($ Yes/no) & $3 / 57$ & $8 / 22$ & 0.003 \\
\hline Vascular disease $(Y e s / n o)$ & $5 / 55$ & $7 / 23$ & 0.048 \\
\hline body mass index (kg/m $\left.{ }^{2}\right)$ & $25.05 \pm 3.04$ & $24.50 \pm 3.67$ & 0.453 \\
\hline CHA $_{2} \mathrm{DS}_{2}$-VASc score & $1.50(1.00)$ & $3.00(2.00)$ & $<0.001$ \\
\hline Data are reported as mean \pm standard deviation, median (interquartile range) or numbers. & \\
\hline
\end{tabular}

\section{Correlation Analysis}

Correlation analysis revealed that $\mathrm{CHA}_{2} \mathrm{DS}_{2}$-VASc scores were related to left ventricular thrombus in patients with this condition $(r=0.413 ; P<0.001)$. 
Multiple logistic regression analyses indicated that $\mathrm{CHA}_{2} \mathrm{DS}_{2}-$ VASc scores $(P=0.001)$ and heart failure $(P=0.023)$ were significant risk factors of left ventricular thrombus (Table 2). In addition, the incidence of left ventricular thrombus increased with higher $\mathrm{CHA}_{2} \mathrm{DS}_{2}-\mathrm{VASc}$ scores (Fig. 1).

Table 2

Multiple logistic regression analyses of factors associated with left ventricular thrombus.

\begin{tabular}{|llllll|}
\hline & $\begin{array}{l}\text { B } \\
\text { coefficient }\end{array}$ & $\begin{array}{l}\text { Standard } \\
\text { error }\end{array}$ & Beta & $\begin{array}{l}\boldsymbol{P} \\
\text { value }\end{array}$ & $\begin{array}{l}95 \% \text { confidence Interval } \\
\text { for B }\end{array}$ \\
\hline Univariate logistic analysis & & & & \\
\hline Age & 0.000 & 0.005 & 0.009 & 0.933 & $-0.010-0.011$ \\
\hline Gender & 0.000 & 0.148 & 0.000 & 1.000 & $-0.294-0.294$ \\
\hline hypertension & 0.163 & 0.099 & 0.173 & 0.103 & $-0.034-0.360$ \\
\hline Diabetes mellitus & 0.000 & 0.114 & 0.000 & 1.000 & $-0.226-0.226$ \\
\hline Heart failure & 0.401 & 0.109 & 0.366 & $<$ & $0.185-0.617$ \\
\hline Stroke & 0.224 & 0.073 & 0.312 & 0.003 & $0.080-0.369$ \\
\hline Vascular disease & 0.288 & 0.145 & 0.208 & 0.049 & $0.001-0.576$ \\
\hline Body mass index & -0.012 & 0.015 & -0.080 & 0.453 & $-0.042-0.019$ \\
\hline $\begin{array}{l}\text { Ventricular } \\
\text { aneurysm }\end{array}$ & 6.38 & 0.145 & 0.425 & $<$ & $0.350-0.925$ \\
\hline $\begin{array}{l}\text { CHA2DS2-VASc } \\
\text { score }\end{array}$ & 0.162 & 0.036 & 0.428 & $<$ & $0.090-0.234$ \\
\hline $\begin{array}{l}\text { Multivariate logistic analysis } \\
\text { CHA }{ }_{2} \text { DS }{ }_{2} \text {-VASc }\end{array}$ & 0.128 & 0.038 & 0.338 & 0.001 & $0.051-0.204$ \\
scores & 0.259 & 0.112 & 0.236 & 0.023 & $0.037-0.481$ \\
\hline \begin{tabular}{l} 
Heart failure \\
\hline
\end{tabular} & & & & & \\
\hline
\end{tabular}

\section{Roc Curve Analysis For Left Ventricular Thrombus}

The ROC curve of $\mathrm{CHA}_{2} \mathrm{DS}_{2}$-VASc scores showed an area under curve (AUC) of 0.746 ( $95 \%$ confidence interval: $0.638-0.853, P<0.001$; Fig. 2), with a sensibility of $86.7 \%$, a specificity of $50.0 \%$, and a cut-off of 1.5 , suggesting that the $\mathrm{CHA}_{2} \mathrm{DS}_{2}-\mathrm{VASc}$ scores contributed to the prediction for left ventricular thrombus after acute anterior STEMI.

\section{Discussion}


This study provided further evidence of the predictive value of $\mathrm{CHA}_{2} \mathrm{DS}_{2}-\mathrm{VASc}$ score as a predictor for left ventricular thrombus after acute anterior STEMI. Our results showed that the AUC of $\mathrm{CHA}_{2} \mathrm{DS}_{2}-\mathrm{VASc}$ score was 0.746 , sensibility was $86.7 \%$, and specificity was $50.0 \%$, suggesting that $\mathrm{CHA}_{2} \mathrm{DS}_{2}-\mathrm{VASc}$ score was a predictor for left ventricular thrombus after acute anterior STEMI. Moreover, our results showed patients with heart failure had a high incidence of left ventricular thrombus after acute anterior STEMI.

Although our research showed that $\mathrm{CHA}_{2} \mathrm{DS}_{2}-\mathrm{VASc}$ score was related to left ventricular thrombus after acute anterior STEMI, the precise mechanism remains unknown; a study suggested that the possible mechanism is platelet activity. Asher et al. ${ }^{14}$ reported that in patients with acute coronary syndrome treated with clopidogrel following $\mathrm{PCl}$, high $\mathrm{CHA}_{2} \mathrm{DS}_{2}-\mathrm{VASc}$ scores correlated with high on-treatment platelet reactivity, whereas low scores correlated with optimal platelet reactivity. Another study ${ }^{15}$ showed that $\mathrm{CHA}_{2} \mathrm{DS}_{2}-\mathrm{VASc}$ score is linearly correlated with residual platelet reactivity $(\mathrm{R}=0.77 ; P<0.001)$. Multivariable analysis demonstrated that $\mathrm{CHA}_{2} \mathrm{DS}_{2}-\mathrm{VASc}$ score is an independent predictor of high residual platelet reactivity.

Another finding of the present study was that patients with heart failure had a higher incidence of left ventricular thrombus after acute anterior STEMI. A previous meta-analysis ${ }^{16}$ showed that the incidence of left ventricular thrombus in patients with acute anterior STEMI was 6.3\%; however, the incidence was $19.2 \%$ when only acute anterior STEMI with LVEF $<50 \%$ was considered. This observation is pathophysiologically plausible because the larger the areas of damage, the larger the probability of regional wall motion disturbances, or even aneurysm formation, will be, leading to a reduced blood flow, ultimately resulting in thrombus formation. ${ }^{17,18}$

The present study has several limitations. First, the sample size of this study was relatively small. Second, the findings were restricted to a yellow race cohort and may not be generalized to other ethnic cohorts. Third, although these findings are important, the retrospective nature of this study limits its generalizability. Fourth, the results were influenced by variabilities among intra- and intersonographers, thereby introducing a significant bias and affecting the measured outcomes.

In conclusion, patients with heart failure have a high incidence of left ventricular thrombus after STEMI. $\mathrm{CHA}_{2} \mathrm{DS}_{2}-\mathrm{VASc}$ score contribute to the prediction for left ventricular thrombus after acute anterior STEMI. Further clinical studies with a better research design are warranted to evaluate and establish the direct cause and effect relationships between $\mathrm{CHA}_{2} \mathrm{DS}_{2}-\mathrm{VASc}$ score and left ventricular thrombus after acute anterior STEMI.

\section{Abbreviations}

STEMI; ST-elevation myocardial infarction, $\mathrm{ROC}=$ receiver operating characteristic, $\mathrm{AUC}=$ area under curve

\section{Declarations}

Ethics approval and consent to participate 
This study was approved by the Medical Ethics Committee of Cangzhou Central Hospital (No. 2020-17001) and conducted in accordance with the Declaration of Helsinki. Informed consent was waived given the retrospective nature of this study.

\section{Consent for publication}

Not applicable.

\section{Availability of data and materials}

The datasets generated and/or analysed during the current study are not publicly available due to privacy or ethical restrictions, but are available from the corresponding author on reasonable request.

\section{Conflict of interest}

The authors declare no conflict of interest.

\section{Funding}

This research did not receive any specific grant from funding agencies in the public, commercial, or notfor-profit sectors

\section{Author Contributions}

NZ and JZ contribute to study design and literature search.

NZ contribute to data collection, interpretation, and analysis.

NZ and JZ contribute to manuscript writing/revisions.

\section{Acknowledgment}

The authors declare no conflicts of interest and funding support.

\section{References}

1. Kajy M, Shokr M, Ramappa P. Use of direct oral anticoagulants in the treatment of left ventricular thrombus: Systematic review of current literature. Am J Ther. 2020;27(6):e584-90.

2. Vallabhajosyula $\mathrm{S}$, Kanwar $\mathrm{S}$, Aung $\mathrm{H}$, et al. Temporal trends and outcomes of left ventricular aneurysm after acute myocardial infarction. Am J Cardiol. 2020;133:32-8.

3. Matsumoto M, Takei N, Mineki T, Yahata T, Oiwa K. Anticoagulant therapy with dual antiplatelet for left ventricular thrombus following acute myocardial infarction. J Cardiol Cases. 2020;22(3):114-6.

4. Delewi R, Zijlstra F, Piek JJ. Left ventricular thrombus formation after acute myocardial infarction. Heart. 2012;98(23):1743-9. 
5. Phan J, Nguyen T, French J, et al. Incidence and predictors of left ventricular thrombus formation following acute ST-segment elevation myocardial infarction: A serial cardiac MRI study. Int J Cardiol Heart Vasc. 2019;24:100395.

6. Ma S, Lu Q, Hu H, Du XJ. Post-infarct left ventricular thrombosis is mechanistically related to ventricular wall rupture. Med Hypotheses. 2020;144:109938.

7. Yuasa $M$, Kitagawa $H$, Aoi R, Chihara T, Imashuku Y, Nosaka S. Left ventricular migrating thrombus detected by intraoperative transesophageal echocardiography. Masui. 2012;61(3):322-5.

8. Miyake Y, Sugioka K, Bussey CD, Di Tullio M, Homma S. Left ventricular mobile thrombus associated with ventricular assist device: diagnosis by transesophageal echocardiography. Circulation journal: official journal of the Japanese Circulation Society. 2004;68(4):383-4.

9. Kurzawski J, Janion-Sadowska A, Zandecki L, Piatek L, Koziel D, Sadowski M. Global peak left atrial longitudinal strain assessed by transthoracic echocardiography is a good predictor of left atrial appendage thrombus in patients in sinus rhythm with heart failure and very low ejection fraction - an observational study. Cardiovascular ultrasound. 2020;18(1):7.

10. Sia $\mathrm{CH}$, Leow AS, Tan BY, et al. The neutrophil-lymphocyte ratio and platelet-lymphocyte ratio predict left ventricular thrombus resolution in acute myocardial infarction without percutaneous coronary intervention. Thromb Res. 2020;194:16-20.

11. Stratton JR, Lighty GW Jr, Pearlman AS, Ritchie JL. Detection of left ventricular thrombus by twodimensional echocardiography: sensitivity, specificity, and causes of uncertainty. Circulation. 1982;66(1):156-66.

12. Alpert JS, Thygesen K, Antman E, Bassand JP. Myocardial infarction redefined-a consensus document of The Joint European Society of Cardiology/American College of Cardiology Committee for the redefinition of myocardial infarction. J Am Coll Cardiol. 2000;36(3):959-69.

13. O'Gara PT, Kushner FG, Ascheim DD, et al. 2013 ACCF/AHA guideline for the management of STelevation myocardial infarction: executive summary: a report of the American College of Cardiology Foundation/American Heart Association Task Force on Practice Guidelines. Circulation. 2013;127(4):529-55.

14. Asher $\mathrm{E}$, Abu-Much A, Bragazzi NL, et al. $\mathrm{CHADS}_{2}$ and $\mathrm{CHA}_{2} \mathrm{DS}_{2}$-VASc scores as predictors of platelet reactivity in acute coronary syndrome. J Cardiol. 2020;S0914-5087(20):30315-30314.

15. Scudiero F, Zocchi C, De Vito E, et al. Relationship between $\mathrm{CHA}_{2} \mathrm{DS}_{2}$-VASc score, coronary artery disease severity, residual platelet reactivity and long-term clinical outcomes in patients with acute coronary syndrome. Int J Cardiol. 2018;262:9-13.

16. Bulluck $\mathrm{H}$, Chan $\mathrm{MHH}$, Paradies $\mathrm{V}$, et al. Incidence and predictors of left ventricular thrombus by cardiovascular magnetic resonance in acute ST-segment elevation myocardial infarction treated by primary percutaneous coronary intervention: a meta-analysis. J Cardiovasc Magn Reson. 2018;20(1):72.

17. Pöss J, Desch S, Eitel C, de Waha S, Thiele H, Eitel I. Left ventricular thrombus formation after STsegment-elevation myocardial infarction: Insights from a cardiac magnetic resonance multicenter 
study. Circ Cardiovasc Imaging. 2015;8(10):e003417.

18. Cambronero-Cortinas E, Bonanad C, Monmeneu JV, et al. Incidence, outcomes, and predictors of ventricular thrombus after reperfused ST-segment-elevation myocardial infarction by using sequential cardiac MR imaging. Radiology. 2017;284(2):372-80.

Figures

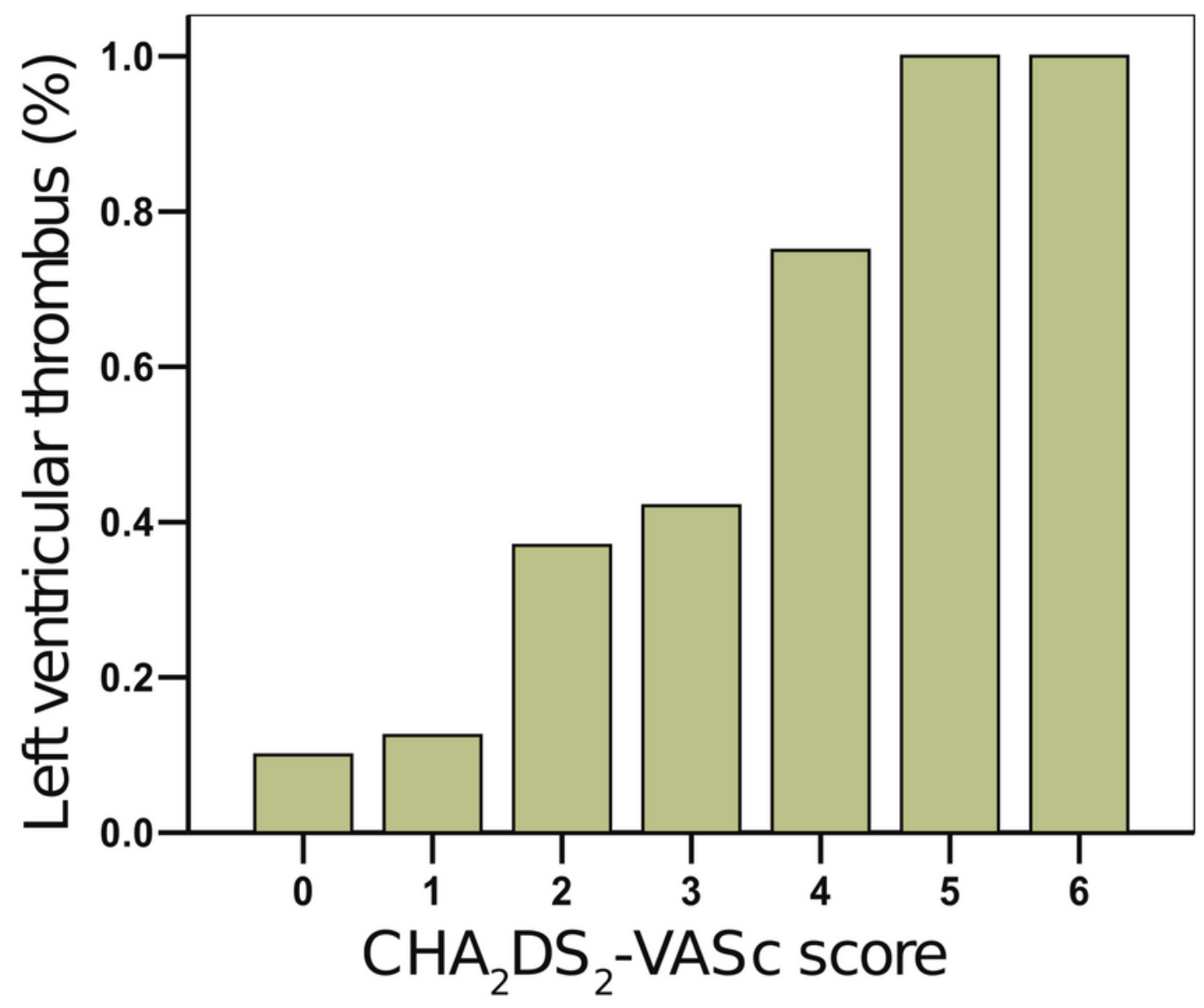


Figure 1

The incidence of left ventricular thrombus according to CHA2DS2-VASc scores

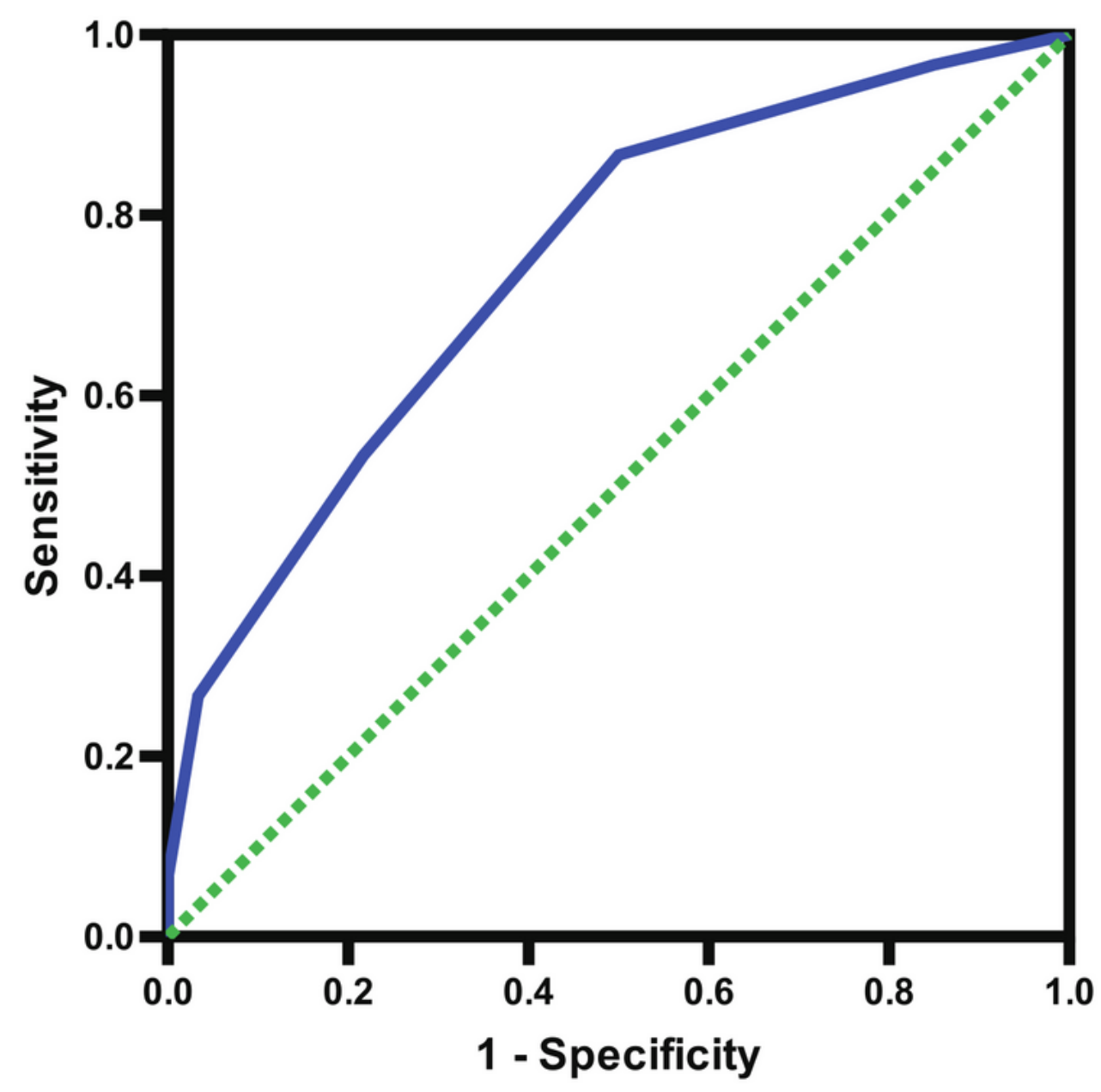

Figure 2

Area under the receiver operating characteristic curve analysis 